\title{
Impact of twisting rate in 10 pairs of unshielded twisted-pair copper cables on insertion loss and crosstalk coupling for G.fast technology
}

\author{
Saizalmursidi Md Mustam, Mohammad Arif Ilyas, Muhammad Syukri Mohd Yazed, Che Ku Afifah \\ Che Ku Alam
}

Faculty of Electrical and Electronic Engineering, Universiti Tun Hussein Onn Malaysia (UTHM), Johor, Malaysia

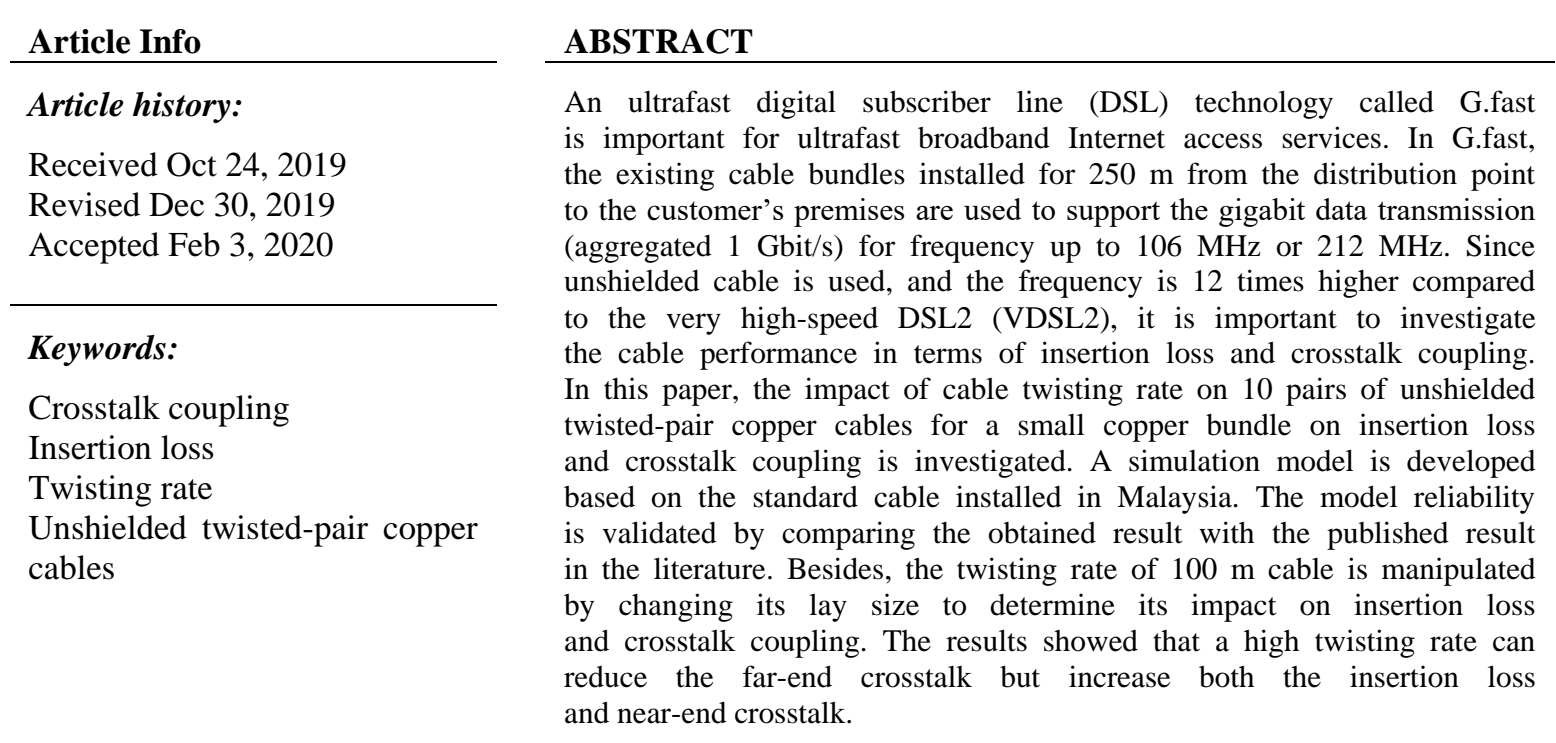

This is an open access article under the CC BY-SA license.

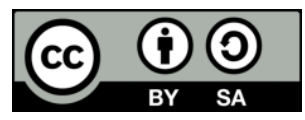

\section{Corresponding Author:}

Saizalmursidi Md Mustam,

Faculty of Electrical and Electronic Engineering,

Universiti Tun Hussein Onn Malaysia (UTHM),

86400 Parit Raja, Batu Pahat Johor, Malaysia.

Email: saizal@uthm.edu.my

\section{INTRODUCTION}

In the telecommunication industry, the DSL technology via twisted-pair copper cables plays a vital role as an infrastructure for high-speed Internet access as well as for worldwide information technology connectivity, especially for suburban areas. This is because of copper cabling is cheaper compared to fiber and can offer fiber to the home (FTTH)-like speeds of data transmission rate [1-3]. The standardization work on DSL technology was initiated by the International Telecommunication Union-Telecommunication Standardization Sector (ITU-T) Study Group 15 (SG15) in 1998. This technology is then further improved to high-bit-rate DSL (HDSL) in 1998, to asymmetric DSL (ADSL) in 1999, to ADSL 2 (ADSL2) in 2002, to ADSL 2+ (ADSL2+) in 2003, to very high speed DSL (VDSL) in 2004, to VDSL2 in 2006, to VDSL2 with vectoring (VDSL2 vectoring) in 2010 and the latest is ultrafast DSL called gigabit fast access to subscriber terminal (G.fast) in 2014 [4-6]. The evolution of DSL technology is to improve Internet access 
services in terms of more data bandwidth as well as to support new applications such as high-definition television (TV) and 4K TV service.

Basically, G.fast technology can support data transferring up to 1 Gbps that is similar to data transmission rate over the fiber cable (optical transmission) [7-8], the maximum bandwidth of around 106 $\mathrm{MHz}$ or $212 \mathrm{MHz}$ and the transmission distance up to around $250 \mathrm{~m}$ from the distribution point DP to the subscriber's premise [9-11]. In addition, this technology provides a hybrid method to telecommunication service operators, where the connectivity after the DP is completed by utilizing the existing twisted-pair copper cable that is previously used for a phone line and ADSL2+ [9]. Figure 1 shows the target installation area of G.fast technology. Although G.fast has the capability of carrying 1 Gbps aggregated data [7,9], the speed of upstream and downstream data is however highly dependent on the cable parameters like attenuation (insertion loss) and crosstalk coupling [10]. In general, insertion loss increases as either frequency or cable length increases. Crosstalk coupling among multiple unshielded twisted-pair copper cables in a cable bundle has been found as the most significant interference $[12,13]$ in VDSL2 system which operates with a maximum bandwidth of $30 \mathrm{MHz}$ [14].

Since G.fast is the extended version of VDSL2 in which the bandwidth can go up to $106 \mathrm{MHz}$ or $212 \mathrm{MHz}$, the crosstalk coupling in G.fast system is expected become the dominant interference at a higher frequency and for longer transmission distance over the unshielded twisted-pair copper cables [15]. Crosstalk coupling can be reduced by increasing the number of twist per meter [16]. Therefore, it is important to investigate the impact of cable twisting rate on the insertion loss and crosstalk coupling for unshielded twisted-pair copper cables in a cable bundle used for G.fast. Generally, the installed cable bundle in Malaysia for DSL technology consists of 50 pairs of unshielded twisted-pair copper cable. These pairs are further bundled up into 5 smaller cable bundles with 10 pairs on each bundle as shown in Figure 2 [9]. The characteristic impedance of the cable is $100 \mathrm{ohm} \mathrm{[10].}$

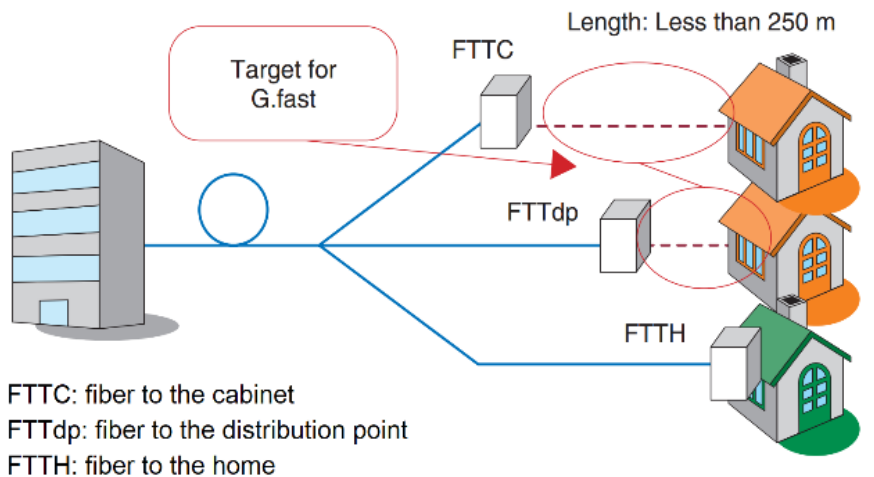

Figure 1. G.fast technology in the fiber to the home access network [4]

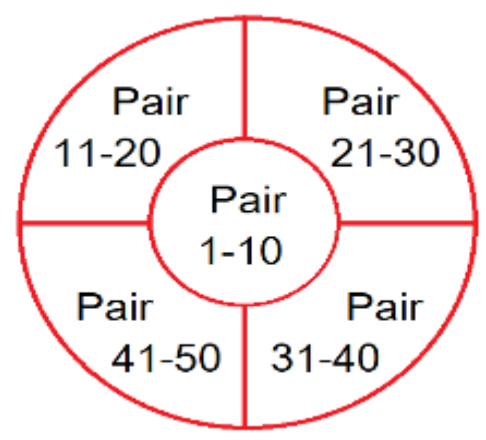

Figure 2. The cross-sectional structure of 50 pairs in a cable bundle [9]

In a network cable, the twisted-pair is commonly used and classified into several categories based on its physical structures and capabilities [17]. For example, both category 1 (CAT1) and category 7 (CAT7) network cables are different in terms of the number of twisting rate, the maximum data rate, and the operating frequency. In twisted-pair cable, twisting plays an important role in reducing the mutual inductive coupling and the loop area between copper cables [16, 18]. Twisting rate is commonly known as the lay length, which is the distance needed to complete one revolution of the strand around the diameter of the conductor. Theoretically, increases the number of twisting rate, decreases the crosstalk among twisted-pair cables. Basically, crosstalk can be divided into two types, near-end crosstalk (NEXT) and far-end crosstalk (FEXT). NEXT is the noise coming from the transmitted signal that coupling between a transmitter of one pair and a transmitter of the adjacent pair, whereas, FEXT is the noise coupling between the transmitter of one pair and a receiver of the adjacent pair. FEXT is dependent on cable length, while NEXT is not dependent on cable length [17]. The minimum requirement of FEXT or NEXT within G.fast is between $-4 \mathrm{dBm}$ to $-8 \mathrm{dBm}$ [8]. On top of crosstalk, the insertion loss of the copper bundle can degrade the signal power as well as data transfer rate. Generally, insertion loss reduces the power of the signal as the length of cable increases. Furthermore, insertion loss will be increased as the frequency increased.

In this paper, a simulation model of cable twisting rate effect on the insertion loss and crosstalk coupling for 10 pairs of unshielded twisted-pair copper cable in a cable bundle is presented. As can be seen 
in Figure 1, the cable length used in G.fast technology is less than $250 \mathrm{~m}$ [19], therefore, the simulation for the cable length greater than $250 \mathrm{~m}$ is beyond the scope of this paper. This work is carried out to profile the crosstalk coupling of the existing copper bundle used for G.fast and then to investigate whether the twisting rate of copper cables in a cable bundle will significantly reduce the interference or not. The rest of this paper is organized as follows: Section 2 provides the methodology of the simulation work. Section 3 discusses the simulation results. Finally, Section 4 summarizes the results and concludes the paper.

\section{METHODOLOGY}

\subsection{Parameters of cable modeling}

Table 1 shows the cable parameters considered in this paper. Basically, the cable modeled under consideration has 10 pairs which are an unshielded twisted-pair copper cable with the length of 100 meters. The 10 pairs are chosen in order to simulate unshielded twisted-pair copper cables for a small copper bundle as shown in Figure 2. A $100 \mathrm{~m}$ cable is chosen for the comparison purpose with the measurement result as published in [9]. The conductor is set to be a copper while its insulator is high-density polyethylene (HDPE). Since, the cable has $100 \mathrm{ohms}$ of line impedance, a $100 \mathrm{ohms}$ of load termination is attached at the end of each cable pair. In this paper, 5 different cable lays are simulated.

Table 1. Unshielded twisted-pair cable parameters

\begin{tabular}{cc}
\hline Parameters & Value \\
\hline Number of pair & 10 pairs \\
Cable length & 100 meter \\
Cable diameter & $20 \mathrm{~mm}$ \\
Type of Insulator & HDPE \\
Load termination & $100 \mathrm{ohm}$ \\
Cable lays & $10 \mathrm{~mm}, 20 \mathrm{~mm}, 30 \mathrm{~mm}, 40 \mathrm{~mm}, 50 \mathrm{~mm}$ \\
\hline
\end{tabular}

\subsection{Simulation setup and benchmarking}

The simulation results for insertion loss (IL), NEXT and FEXT are obtained by using CST Cable Studio based on the setup as shown in Figure 3. According to Figure 3, port 1 is assumed to be the input source (transmitter) and port 2 as the load (receiver). Insertion loss result is obtained by measuring the output side (port 2) for each pair. NEXT is the measurement on the input side (port 1) of another pair. On the other hand, FEXT is the measurement taken on the output side (port 2) of another pair. Termination of $100 \mathrm{ohms}$ is used at the end of each pair.

In order to validate the cable design, a comparison study is made for the simulated insertion loss result with the modeling and measurement results published in [9]. Then, to investigate the impact of twisting rate in 10 pairs of unshielded twisted-pair copper cables on insertion loss and crosstalk coupling for G.fast technology, the different cable lays as listed in Table 1 are simulated.

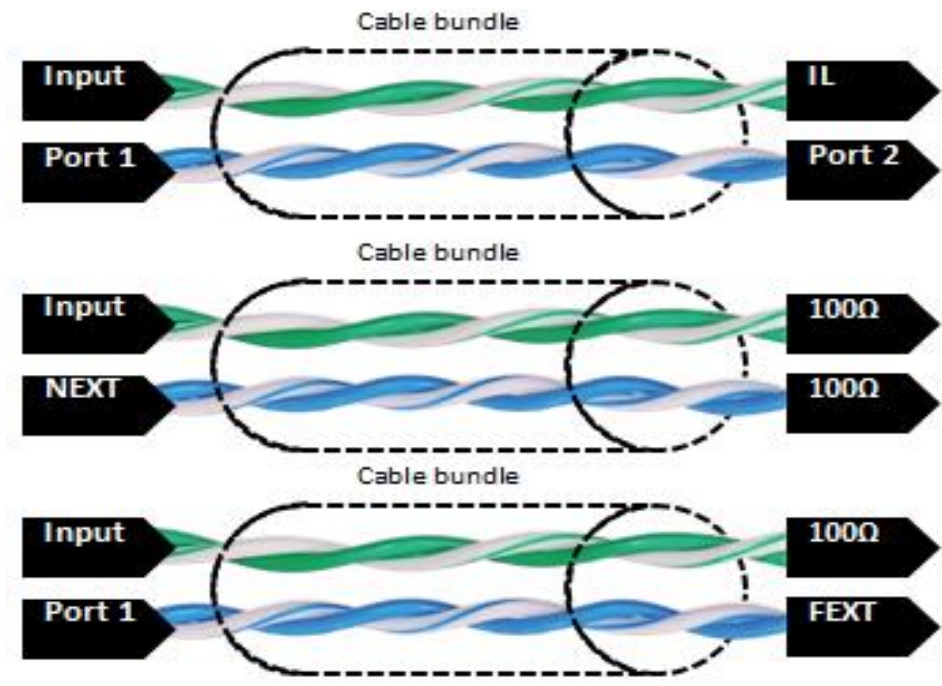

Figure 3. Simulation setup for insertion loss, NEXT, and FEXT 


\section{RESULTS AND ANALYSIS}

In this section, the simulation results are presented and discussed. Figure 4 shows the cross-sectional structure of the cable that has been modelled in commercial software. The 10 pairs of unshielded twisted-pair cable were modeled with copper as the conductor and HDPE as its insulator. The outer layer of the cable is set to be HDPE and the air medium in between the inner and outer layer. Figure 5 shows the schematic of 10 pairs of cable modeled (input ports) under study in this work. The cable length is set to be 100 meters, and 20 ports are used and placed at the end of each cable pair. On top of that, $100 \mathrm{ohms}$ is placed as the line impedance matching.

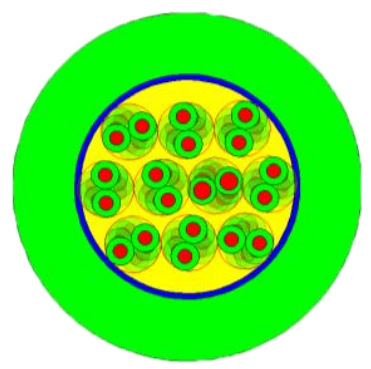

Figure 4. 10 pairs of unshielded twisted-pair cable cross section

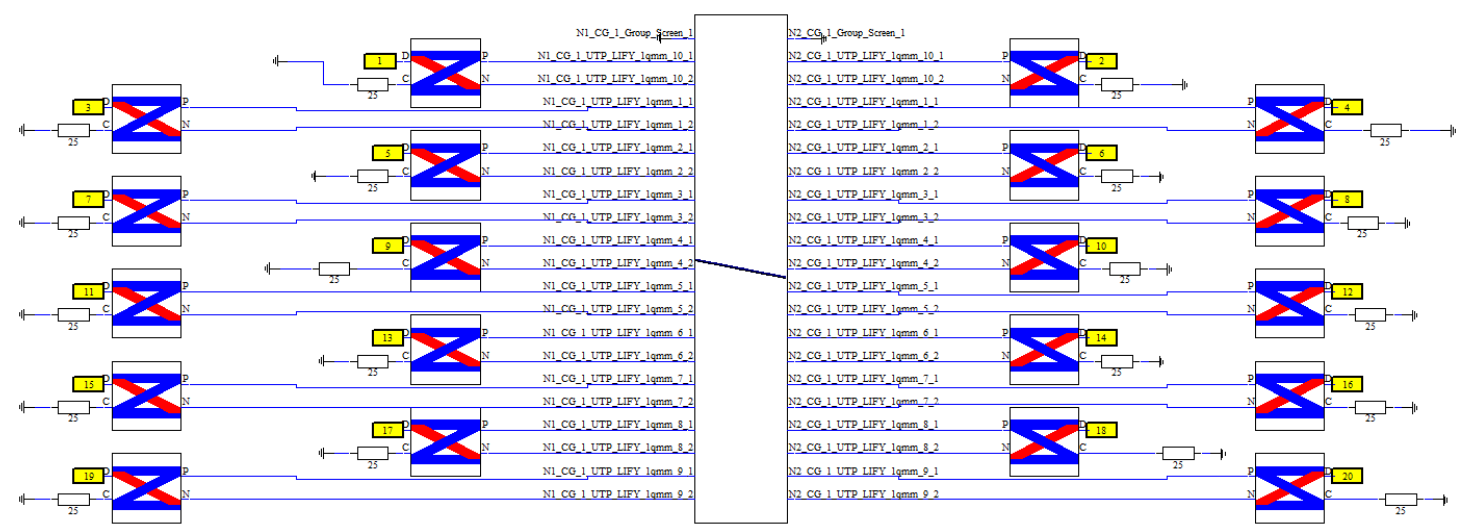

Figure 5. 10 pairs of unshielded twisted-pair copper cables modeling

\subsection{The insertion loss of cable with different twisting rates}

To validate the developed model, the insertion loss of standard cable design is compared with the published measurement results in [9]. Based on Figure 6, the simulated design is in good agreement for the frequency higher than $125 \mathrm{MHz}$. Then, five different cable lays configuration have been simulated and Figure 7 shows the insertion loss for different cable lays versus frequency. For the frequencies from $106 \mathrm{MHz}$ to $212 \mathrm{MHz}$, the highest insertion loss is recorded for $10 \mathrm{~mm}$ of cable twisting rate, which is about $19 \mathrm{~dB}$ greater than $20 \mathrm{~mm}$ of cable twisting (a standard benchmark as gather from the result shown in Figure 6, which is around $28 \mathrm{~dB}$ ). Generally, it can be concluded that in term of insertion loss, the cable does not perform well when the high number of twists per meter is considered. The standard cable lay length or cable twisting rate is $20 \mathrm{~mm}$ [9]. At higher frequency, increases the number of twists per meter will increase both the capacitance within the cable pair as well as the insertion loss.

\subsection{Crosstalk of cable with different twisting rates}

In this section, the simulation results of NEXT and FEXT are presented. For NEXT, $10 \mathrm{~mm}$ of cable twisting rate records the highest crosstalk level compared to the other cable lays as depicted in Figure 8. These results imply that the higher the cable lay (low twisting rate) the lower the crosstalk level. Therefore, crosstalk due to NEXT is not critical to be solved by using a twisting rate. It can be solved by using a band stop filter [20-22]. Figure 9 shows the result of FEXT for different cable lay lengths versus frequency. There is no significant pattern can be derived from this result. However, by comparing the lay lengths from $50 \mathrm{~mm}$ to $10 \mathrm{~mm}$ within the bandwidth of $100 \mathrm{MHz}$ to $225 \mathrm{MHz}$, it can be observed that the lowest cable lay (high 
twisting rate) produces a low FEXT across the cable. By considering the insertion loss, NEXT and FEXT, it can be concluded that the twisting rate of $20 \mathrm{~mm}$ gives the optimum result in 10 unshielded twisted-pair copper cables. Increasing the number of cable lay (low twisting rate) resulting in high FEXT but low in both the insertion loss and NEXT [23-25]. In order to observe the impact of different transmission distances (cable lengths) on crosstalk coupling due to FEXT, cable lengths of $50 \mathrm{~m}, 100 \mathrm{~m}, 150 \mathrm{~m}, 200 \mathrm{~m}$, and $250 \mathrm{~m}$ with a $20 \mathrm{~mm}$ of twisting rate (standard cable lay length) are considered. It can be seen in Figure 10 that the longer the transmission distances or cable lengths, the higher the FEXT.

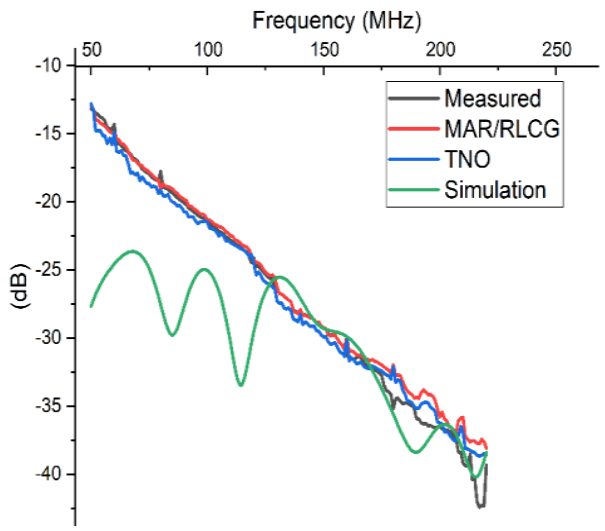

Figure 6. Insertion loss for the standard cable versus frequency in comparison with the average results published in [9]

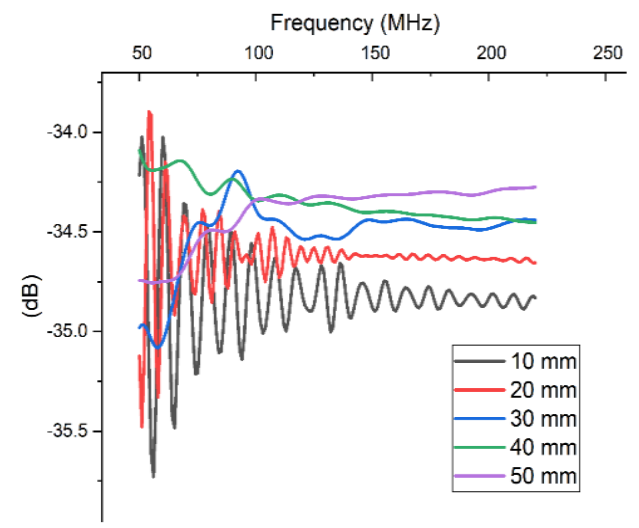

Figure 8. NEXT for different cable lays versus frequency

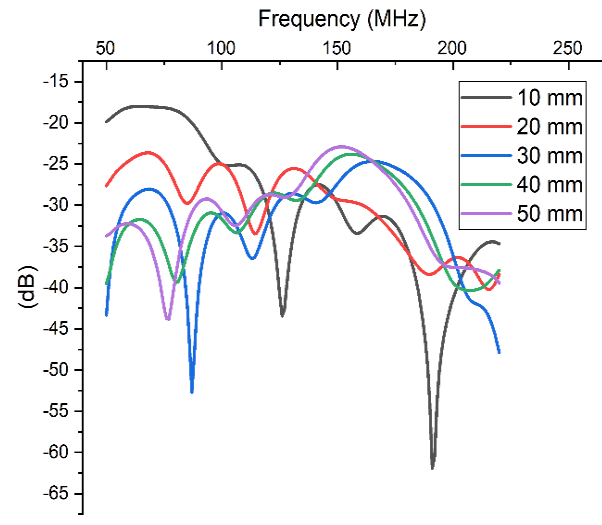

Figure 7. Insertion loss for different cable lays versus frequency

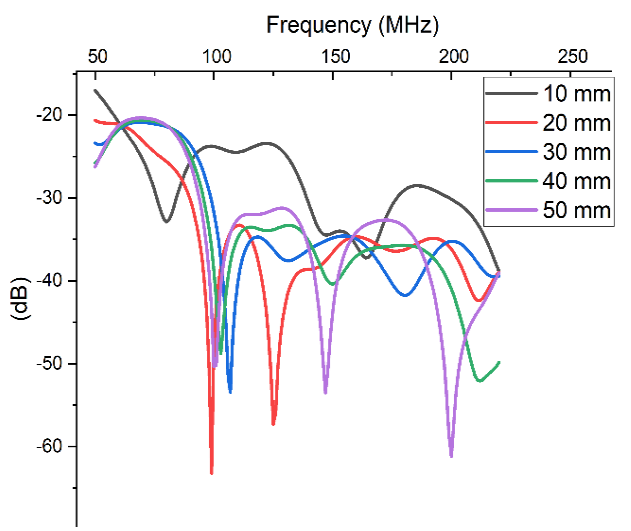

Figure 9. FEXT for different cable lays versus frequency

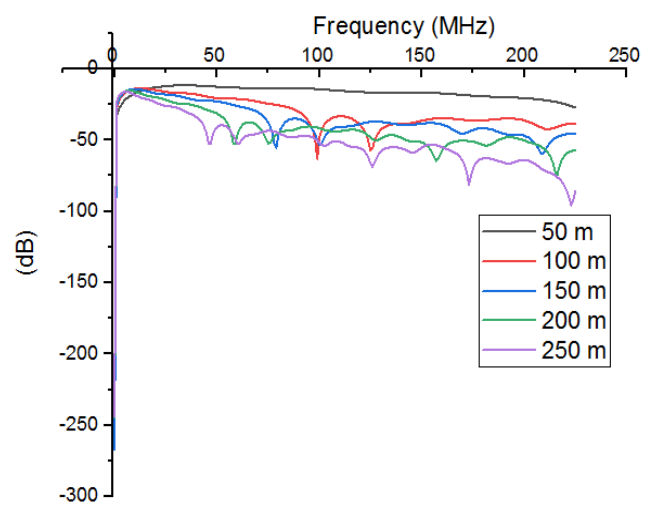

Figure 10. FEXT for five different cable lengths versus frequency 


\section{CONCLUSION}

In this paper, the simulation of twisting rate impact in 10 unshielded twisted-pair copper cables was successfully carried out. It can be concluded that increasing the number of cable lay (low twisting rate) resulting in high FEXT but low in both the insertion loss and NEXT, especially at high frequencies. In addition, increasing the cable length will increase the crosstalk coupling due to FEXT. This research is helpful and can be referred to as a guideline by Malaysia's telecommunication service provider and other researchers for further research and development.

\section{ACKNOWLEDGEMENTS}

The authors would like to thank the Research Management Centre (RMC), Universiti Tun Hussein Onn Malaysia (UTHM) for the financial support of this project under the Tier 1 research grant scheme (Vot. No. H142).

\section{REFERENCES}

[1] M. M. Al-Quzwini, "Design and Implementation of a Fiber to the Home (FTTH) Access Network based on GPON," International Journal of Computer Applications, vol. 92, no. 6, pp. 30-42, Apr, 2014.

[2] A. S. Shibghatullah, M. M. Mohammed, M. Doheir, and A. N. Majed, "Fiber to the Home (FTTH) Architecture for Mosul, Iraq," International Journal of Human and Technology Interaction, vol. 1, no. 1, pp. 37-42, 2017.

[3] W. Awalia, and A. B. Pantjawati, "Performance Simulation of Fiber to the Home (FTTH) Devices Based on Optisystem," in IOP Conference Series: Materials Science and Engineering, pp. 384, 2018.

[4] K. Yoroshiro, "G.fast Ultrafast Access Technology Standardlization in ITU-T," Global Standardization Activities, vol. 14, no. 7, pp. 1-5, 2016.

[5] T. C. Chuah, Y. H. Ng, A. N. Zainal Abidin, and A. Asrokin, "Performance of Linear and Non-linear Precoders in G.fast Ultra-broadband DSL Networks,” International Journal of Communication Systems, vol. 30, no. 7, pp. 1-21, 2017.

[6] A. J. Al-Askery and A. M. Hammadi, "On the Performance of Coded Copper Wire Systems for G.fast Communications," Indonesian Journal of Electrical Engineering and Computer Science, vol. 14, no. 3, pp. 1272-1280, 2019.

[7] ITU-T G.9701, "Fast Access to Subscriber Terminals (G.fast) - Physical Layer Specification," International Telecommunications Union-Telecommunication Standardization Sector (ITU-T), vol. 9701, no. 2014, 2017.

[8] ITU-T G.997.2, "Physical Layer Management for G.Fast Transceiver- Series G: Transmission Systems and Media, Digital Systems and Networks," International Telecommunications Union-Telecommunication Standardization Sector (ITU-T), 2015.

[9] A. Asrokin, M. K. A. Rahim, A. N. Z. Abidin, N. Hashim and S. A. Azis, "Cable modelling comparison for twisted-pair copper plant in malaysia," 2015 IEEE International Conference on Control System, Computing and Engineering (ICCSCE), George Town, 2015, pp. 359-364.

[10] A. N. Z. Abidin et al., "G.fast channel modelling based on copper cable characteristics," 2015 IEEE International Conference on Control System, Computing and Engineering (ICCSCE), George Town, 2015, pp. 212-217.

[11] W. M. Osman, A. B. Al Nabi, and K. H. Billal, "Optical Fiber Review," Journal of Electrical and Electronic Systems, vol. 7, no. 1, pp. 249, 2018.

[12] A. F. Mahmoud, M. I. Abdallah, and S. I. S. O. Iec, "Performance Testing of Twisted Pair Cables," Journal of Computer Systems, Networks, and Communications, vol. 2008, no. 1, pp. 1-8, 2008.

[13] A. Grami, "Fundamental Aspects of Digital Communications," Introduction to Digital Communications, Academic Press, ch. 2, pp. 11-39. 2016.

[14] V. Oreshkov, and V. Balashov, "Efficiency of G.fast Technology Application on TPP Type Telephone Cables," International Conference on Information and Telecommunication Technologies and Radio Electronics (UkrMiCo), Odessa, pp. 1-5. 2017.

[15] M. Magdowski, G. Henning, and R. Vick, "Measurement of the Stochastic Electromagnetic Field Coupling to an Unshielded Twisted Pair Cable with a Matched Termination," ESA Workshop on Aerospace EMC (Aerospace EMC), Valencia, pp. 1-6. 2016.

[16] D. Johns and P. DeRoy, "Simulating Crosstalk and EMI in Cables," Microwave Journal Cables and Connectors Supplement, Horizon House Publications, Inc., March 2013

[17] M. A. F. Musa, N. S. Zamani, A. Asrokin, N. Hashim, W. M. I. W. M. Said and A. N. Z. Abidin, "FEXT and NEXT analysis for VDSL2 technology on 50 twisted pairs TM copper cable," 2015 IEEE 12th Malaysia International Conference on Communications (MICC), Kuching, 2015, pp. 175-180.

[18] R. Nagase, Y. Abe and M. Kihara, "History of Fiber Optic Physical Contact Connector for Low Insertion and High Return Losses," 2017 IEEE HISTory of ELectrotechnolgy CONference (HISTELCON), Kobe, 2017, pp. 113-116.

[19] V. Oksman et al., "The ITU-T's new G.fast standard brings DSL into the gigabit era," in IEEE Communications Magazine, vol. 54, no. 3, pp. 118-126, March 2016.

[20] V. Piet, B. Tom, K. Van Acker, G. Ginis, M. Moonen, and R. Cendrillon, "Partial Crosstalk Cancellation for Upstream VDSL," EURASIP Journal on Advances in Signal Processing, vol. no. 10, pp. 1520-1535, 2004. 
[21] B. Li, P. Tsiaflakis, M. Moonen, J. Maes and M. Guenach, "Dynamic Resource Allocation Based Partial Crosstalk Cancellation in DSL Networks," 2010 IEEE Global Telecommunications Conference GLOBECOM 2010, Miami, FL, 2010, pp. 1-5.

[22] S. Bahrami and S. Fallahzadeh, "Near End Crosstalk Reduction Using Slow Wave Structures," Journal of Electromagnetic Waves and Applications, vol. 30, no. 12, pp. 1-8, Jun 2016.

[23] A. Young, "Attenuation (Insertion Loss) Measurement and Testing-DTX CableAnalyzer," Fluke Networks, pp. 13, Feb 2014.

[24] M. Mullins, "Cable Testing 101 : Understanding Near and Far End Crosstalk," Fluke Networks, pp. 10, Sep 2016.

[25] E. Wright, D. Reynders and S. Mackay, "Practical Telecommunications and Wireless Communications," Newnes, pp. 27-62, 2004.

\section{BIOGRAPHIES OF AUTHORS}
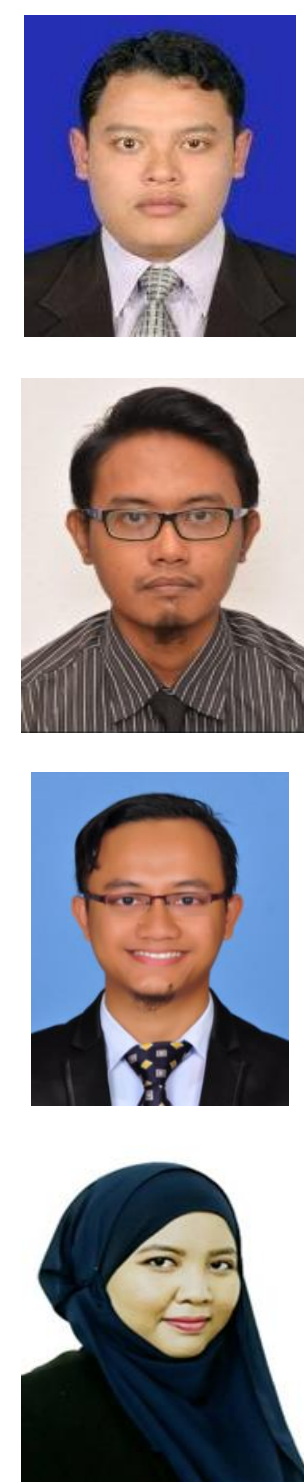

Saizalmursidi Md Mustam received the B.Eng. (Electrical) degree from Kolej Universiti Teknologi Tun Hussein Onn (KUiTTHO), Malaysia, in 2006, the M.Eng. degree in electrical from Universiti Tun Hussein Onn Malaysia (UTHM) in 2011, and the Ph.D. degree in electrical engineering from Universiti Teknologi Malaysia (UTM) in 2016. Currently, he is a lecturer at UTHM. His research interests are in the area of molecular communication and electromagnetic compatibility.

Mohammad Arif Ilyas was born in Malaysia in 1991. He received the B.Eng. degree from Universiti Tun Hussein Onn Malaysia (UTHM) in 2015. He is currently working toward his Ph.D. degree in Electrical Engineering at the same University. His main area of research interest is Optical wireless communication, especially on visible light communication. Currently, his research involving several digital modulation designs using FPGA.

Muhammad Syukri Mohd Yazed was born in Malaysia in 1992. He received the B.Eng. degree from Universiti Tun Hussein Onn Malaysia (UTHM) in 2015. He is currently working toward his M.Eng degree in Electrical Engineering at the same University. His main area of research interest is in electrical and electronic applications and devices. He is active in a transmission with light programmed with the community around the university.

Che Ku Afifah Che Ku Alam received the B.Eng. degree in electronics from Universiti Tun Hussien Onn Malaysia (UTHM) in 2016. She is currently working toward her M.Eng degree in Electrical Engineering in UTHM and a research assistant for the collaboration projects with the Telekom Malaysia Research and Development (TM R\&D). 